\title{
Aryepiglottic Fold as a Rare Location for a Monomorphic Adenoma-Case Report
}

\author{
Hosaagrahara Subbegowda Satish, Niveditha Jayanna, Borlingegowda Viswanatha, \\ Ramabhadraiah Anil Kumar \\ Ear, Nose and Throat Department, Bangalore Medical College \& Research Institute, Bangalore, India \\ Email: drbviswanatha@yahoo.co.in
}

Received February 7, 2013; revised March 10, 2013; accepted March 19, 2013

\begin{abstract}
We report a case of Monomorphic adenoma of aryepiglottic fold. Histopathological findings are described. This is the first case, to our knowledge, of a Monomorphic adenoma presenting at aryepiglottic fold. Complete excision of the mass was done through laryngofissure approach.
\end{abstract}

Keywords: Monomorphic Adenoma; Laryngofissure; Aryepiglottic Fold

\section{Introduction}

Tumors of minor salivary glands are rare, accounting for $2 \%-4 \%$ of head and neck tumors [1]. Monomorphic adenomas tend to occur over the age of 50 years with a slight female predilection of 2:1. They usually occur in the parotid $(75 \%)$ or submandibular gland (approximately $5 \%$ ). These lesions are quite rare in the minor salivary glands excluding canalicular adenomas. This tumor most commonly involves the minor salivary glands of the upper lip (74\%) or buccal mucosal (12\%) [2]. They typically present as a slowly growing solitary painless mass. Grossly, these tumors are a well-circum-scribed, solid homogeneous gray-white to tan-brown occasionally mimicking an enlarged lymph node. Rarely, cystic change may be seen grossly.

Such tumors may be suspected when occurring at the usual site of the salivary glands. However, minor salivary glands are found in various locations, extending from the paranasal sinuses to the larynx. We report one case of Monomorphic adenoma developed from the aryepiglottic fold

\section{Case Report}

A 52-year-old male had intermittent dysphagia. The first symptoms had begun 12 months earlier, without decline of the general status. On physical examination, laryngeal framework was normal and no cervical lymphadenopathy. A tumor of the right aryepiglottic fold was noted at time of indirect laryngoscopy. There was no impairment of the laryngeal motion. A computed tomography (CT) scan of the neck revealed a 2-cm-diameter homogeneous mass arising from the right aryepiglottic fold (Figures 1(a) and (b)). CT showed no cervical lymph nodes. Direct laryngoscope evidenced a well delineated tumor of the right aryepiglottic fold, extending toward the epiglottis, not invading the pharyngeal wall. The lesion was biopsied and all samples demonstrated as Monomorphic adenoma of aryepiglottic fold.

A surgical treatment was decided on, consisting of laryngofissure with excision of mass under GA. Intraoperatively we could see mass arising from right aryepiglottic fold. Figure 2(a) showing laryngofissure approach and Figure 2(b) showing speciman

Histopathological picture Figure 3 showed cords of single layer columnar or cuboidal cells forming duct like structures in a back ground of fibrous stroma.

The postoperative period was uneventfull and one year after surgery the patient was asymptomatic and free of clinical and radiologic evidence of recurrence.

\section{Discussion}

Tumors of the minor salivary glands are responsible for $2 \%-4 \%$ of tumors of the head and neck, $10 \%$ of tumors of the oral cavity, and $15 \%$ - $23 \%$ of tumors of the salivary glands [1]. The most frequent location of Monomorphic adenoma of a minor salivary gland is the hard palate, followed by the lips, oral mucosa, floor of the mouth, tonsil, pharynx, retromolar area, and nasal cavity [2]. Monomorphic adenomas do not usually present a sexual predisposition and they can appear at any age with the same clinical behavior [3]. They are generally round, slow-growing tumors that are painless and firm in consistency. Microscopically there are cords of single-layer 


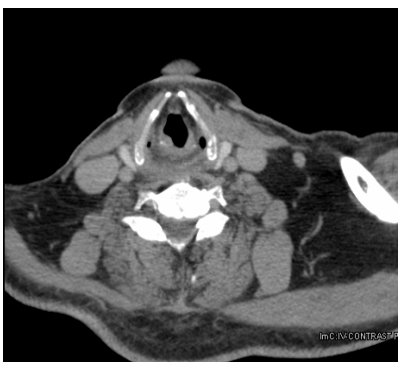

(a)

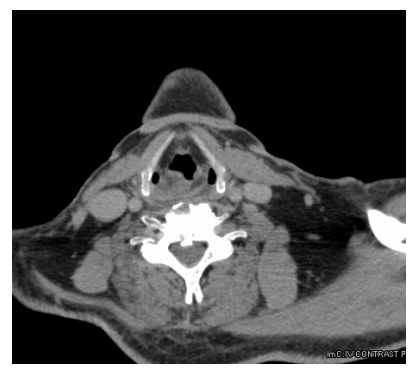

(b)
Figure 1. (a) and (b) Axial CT scan shows a homogeneous tumor arising from the right aryepiglottic fold (white arrow).

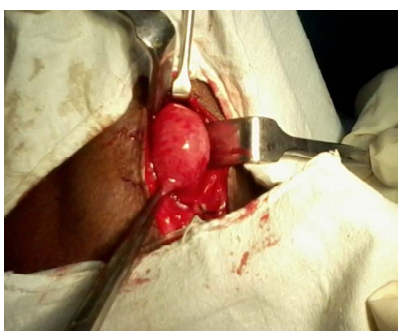

(a)

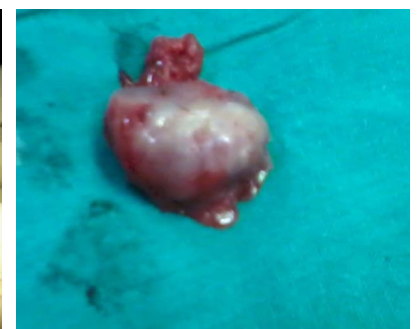

(b)
Figure 2. (a) Shows laryngofissure approach and (b) shows specimen.

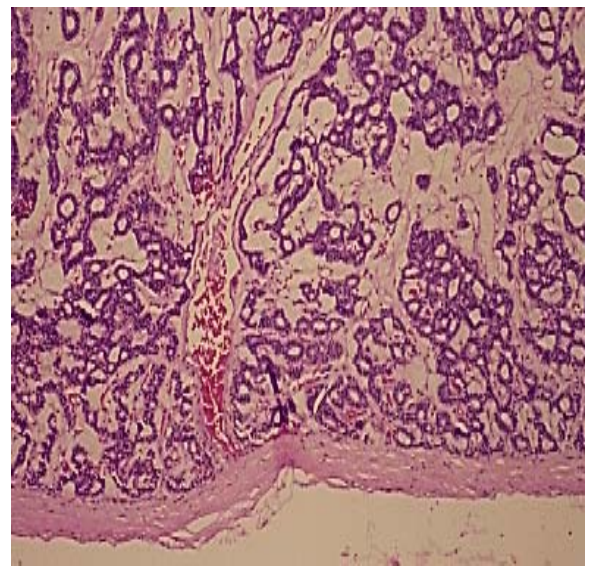

Figure 3. Cords of single-layer columnar or cuboidal cells forming duct-like structures in a background of fibrous stroma.

columnar or cuboidal cells forming duct-like structures in a background of fibrous stroma.

Tumors of the minor salivary glands do not have a fi- brotic capsule (they have a very thin capsule) and they may have a false infiltrative appearance. One conesquence of this is that CT and MRI imaging diagnosis will be necessary to evaluate as exactly as possible the extension and anatomic relations of the tumor in order to plan a suitable surgical approach. After studying the case, we decided to excise the tumor through laryngofissure approach. The prognosis will be excellent if resection is adequate. Irradiation is reserved for recurrences and inoperable cases [4]. Malignant transformation has been reported $(2 \%$ - $9 \%)$, generally to adenocarcinoma or undifferentiated carcinoma. The risk of malignization increases with the duration of the tumor and mean age of the patient [5]. Regular follow-up is required to detect local recurrence and malignant transformation.

\section{Conclusion}

Monomorphic adenoma is histological diagnosis. Clinically it presents as a nonpainful submucosal nodule [6]. The majority of monomorphic adenomas display nonaggressive behavior and are adequately treated with complete surgical excision.

\section{REFERENCES}

[1] G. L. Ellis and P. L. Auclair, "Mixed Tumors,” In: Tumors of the Salivary Glands. Atlas of Tumor Pathology. Chapter IV: Benign Epithelial Neoplasm, 3rd Series, Fascicle 17, Armed Forces Institute of Pathology, Washington, 1996, pp. 39-63.

[2] D. W. Eisele and M. E. Johns, "Salivary Gland Neoplasms,” In: B. J. Bailey, Ed, Head \& Neck SurgeryOtolaryngology, Lippincott Williams \& Wilkins, Philadelphia, 2001, pp. 1279-1297.

[3] J. C. Califano and D. W. Eisele, "Benign Salivary Gland Neoplasms," Otolaryngology Clinics of North America, Vol. 35, No. 5, 1999, pp. 861-873. doi:10.1016/S0030-6665(05)70178-X

[4] C. A. Perez, “Treatment of Pleomorphic Adenoma,” Principles of Practise of Radiation Oncology JB Lippincott Company, Philadelphia, 1987, p. 521.

[5] J. A. Regesi and J. J. Sciubba, "Salivary Gland Diseases, in Oral Pathology," Saunders, Philadelphia, 1993, pp. 270-271.

[6] G. L. Ellis, P. L. Auclair and D. R. Gnepp, "Surgical Pathology of the Salivary Glands," WB Saunders, Philadelphia, 1991. 